\title{
Self-reported use of handheld computers: a survey of Nova Scotia pharmacists ${ }^{1}$
}

\author{
Alicia McCallum, Ingrid Sketris, Glenn Rodrigues, David K. Yung, Barbara Hill-Taylor, \\ and Steve Doucette
}

\begin{abstract}
Introduction: With an ever-increasing array of pharmaceutical and biomedical products and literature, health professionals including pharmacists struggle to obtain, evaluate, and apply relevant information. Handheld computers provide pharmacists with mobile access to evidence-informed medical information, decision support tools, and the ability to monitor therapeutic outcomes at the point of care. There is limited literature on the usage of this technology by Canadian pharmacists. The objective of this survey was to determine the scope and nature of handheld computer use by Nova Scotia pharmacists. Method: In 2008, Nova Scotia pharmacists were contacted with a written survey. Descriptive statistics were used to compare users and non-users. Multivariate regression analysis was used to determine demographic and pharmacy practice variables that might be associated with pharmacists' use of handheld computers. Results: The survey was returned by 296 pharmacists $(27.7 \%)$. Handheld computers were reported to be used by $51 \%$ of respondents. Those respondents who have been in practice longer were less likely to adopt handheld computer use (adjusted OR $=0.97$, $95 \% \mathrm{CI}=0.94-0.99, p=0.01)$. Barriers and facilitators to usage were explored. More than two-thirds of pharmacists who had not yet used handheld computers perceived a future value for these devices within their practice. Discussion: Pharmacists are adopting the use of handheld computers. With enhanced clinical practice opportunities for pharmacists including independent prescribing, these tools may offer needed functionality. Further work is required to understand the value of handheld computers as information resources, which may improve the effectiveness and efficiency of patient care.
\end{abstract}

\section{Introduction}

With an ever-increasing array of pharmaceutical and biomedical products and literature, health professionals including pharmacists struggle to obtain, evaluate, and apply relevant clinical information. The Health Canada Drug Product Database currently lists over 12000 products for human use [1]. It is estimated that over 6000 articles related to health are published weekly in the biomedical literature [2]. Alper et al. calculated that primary care physicians would need 29 hours per day to remain current with primary care literature [3]. Pharmacists also struggle to keep up with the literature published in their broad field. Their predecessors maintained expertise by reading several select journals. Today, that is impossible. "Information technology helps overcome the limits of human memory, reduces the use of opinion-based reasoning, and enables people to base decisions firmly on scientific evidence" [2, p.79]. Handheld computers provide pharma- cists with mobile access to evidence-informed medical information, computerized decision support tools, and the ability to monitor therapeutic outcomes at the point of care.

Handheld computers offer multifaceted functionality; originally, these tools replaced calculators, address books, calendars, and note pads. Beginning in the 1990s, innovators used personal digital assistants (PDAs) such as the Palm OS ${ }^{\circledR}$ (Palm, Inc, Sunnyvale, Calif.) or Pocket $\mathrm{PC}^{\circledR}$ (Microsoft Corp., Redmond, Wash.) equipped with ePocrates $\mathrm{Rx}^{\circledR}$ (Epocrates, San Mateo, Calif.) or MobilePDR ${ }^{\circledR}$ (Skyscape, Marlborough, Mass.) software as mobile information storage and point-of-care drug information systems [4-7]. However, in addition to user interface limitations such as a small screen and stylus input, early devices required time-consuming synchronization with a base computer in order to download data and receive updates. Modern devices, which were not available or commonly used by pharmacists in Nova Scotia at the time of this survey, such as the Blackberry ${ }^{\circledR}$

A. McCallum, BSc(Pharm). Queen Elizabeth Hospital, Charlottetown, PE, Canada.

I. Sketris', Pharm D, MPA (HSA) and B. Hill-Taylor, BSP, MLIS. IMPART, College of Pharmacy, Dalhousie University, Halifax, Nova Scotia, Canada.

G. Rodrigues, BSc, BSc(Pharm) and D. K. Yung, PhD. College of Pharmacy, Dalhousie University, Halifax, NS, Canada.

S. Doucette, MSc. Research Methods Unit (RMU) Centre for Clinical Research, Halifax, NS, Canada.

${ }^{1}$ This article has been peer reviewed.

${ }^{2}$ Corresponding author (e-mail: Ingrid.sketris@dal.ca). 
(Research in Motion, Waterloo, Ont.), iPad ${ }^{\circledR}$ (Apple Inc., Cupertino, Calif.), and Android ${ }^{\circledR}$ devices (Google, Mountain View, Calif.), have revolutionized the handheld computer market with robust computing power and expanded functionality. Today's devices allow for a "webcentric computing experience" with touch screen interface, cellular telephone, and audio-visual record and playback capabilities [4].

Initially, pharmacists' use of handheld computers was reported as predominantly for the documentation of clinical activities. Studies in Canada and the US found handheld computers valuable in facilitating point-of-care documentation of drug-related problems in both community and hospital settings [8-12]. An observational study of clinical pharmacists' use of handheld computers in an emergency department found that the devices were helpful for both intervention and cost-avoidance documentation [13]. A recent survey of American pharmacists found that handheld computers were being used as personal organizers, to obtain drug information and to facilitate medical calculations [14].

A survey of the use of iPharmacist ${ }^{\circledR}$ handheld software by Canadian pharmacists was performed in the fall of 2009 [15]. iPharmacist ${ }^{\circledR}$, produced by the pharmaceutical company Apotex, Inc. (Toronto, Ont., http://www.apotex. com), offers business and clinical software, as well as news and other features that support the activities of pharmacists. Of respondents, $19 \%$ reported using the Lexi-Drugg ${ }^{\circledR}$ (http://www.lexi.com) component of iPharmacist ${ }^{\circledR}$ frequently for providing cognitive services. Lexi-Drugs ${ }^{\circledR}$ is a drug database that provides access to information such as adverse reactions, contraindications, dosing, medication safety issues, pharmacodynamics, kinetics, and alerts. This survey established a "time-saving" element to the use of iPharmacist ${ }^{\circledR} ; 51 \%$ of respondents reported that the use of this software saved time, with $30 \%$ reporting a saving of 16-30 minutes per day.

A clear picture of community and hospital pharmacist's use of handheld computers in Canada has not yet been established. Many authors have pointed to gaps in understanding: who is using these devices? for what purposes? and, most importantly, what value do they offer to patients, pharmacists and their employers? $[4,5,16,17]$. The objective of this survey was to determine the scope and nature of handheld computer use by Nova Scotia pharmacists. Specifically, the survey collected information on the demographics of handheld computer users and non-users, the tasks being performed, and the facilitators and barriers to the use of these clinical tools.

\section{Methods}

\section{Design}

A single mailing of the survey was distributed to all registered pharmacists in the province in September 2008. This study was approved by the Dalhousie Health Sciences Human Research Ethics Board (Project\#2008-1764).

The 32 structured and open-format questions on the English-language survey instrument were adapted from published surveys that had explored PDA usage by health care professionals [18-24]. The survey instrument was reviewed by a panel of experts and pre-tested on a small group of practicing pharmacists. No changes were made to the content of the questions. A copy of the survey instrument is available from the corresponding author on request.

\section{Terminology}

The survey was directed to personal digital assistant (PDA) use because PDAs were the handheld computers in use by pharmacists at that time. Internet-enabled handheld computer devices were relatively new, expensive and not in common use. Although the term personal digital assistant was chosen for the survey, the MeSH term handheld computer, defined as "microcomputers... that are very small and portable, fitting in a hand, and that have much more function than a calculator" was considered more appropriate for this paper [25].

The terms user and non-user are employed to describe respondents who reported use of a handheld computer with pharmacy software and those who do not. Pharmacies were classified as working in an independent, banner, franchise, chain, food/mass/department or hospital pharmacy [26].

\section{Data collection}

The survey instrument was distributed to all 1069 registered pharmacists with an address in Nova Scotia. It was mailed with the regular newsletter of the Pharmacy Association of Nova Scotia. Willingness to complete the survey was considered to imply consent. A draw for a $\$ 100.00$ gift certificate was used as an incentive for completion of the survey. The self-administered surveys were returned by prepaid self-addressed envelopes to the primary author by mail. Two surveys were unusable; one was returned to sender, the other was missing the first page.

\section{Data analysis}

Survey responses were summarized using frequencies and percentages where appropriate. Handheld computer users were compared to non-users for significant trends and differences in sex, age, location, number of working hours and daily average prescription count in dispensary, number of years of practice, and primary employment settings, and preferences for training using the $t$-test, chi-square and Cochrane-Armitage trend analysis where appropriate. An adjusted analysis was performed by multiple logistic regressions. Adjusted odds ratios (OR) and 95\% confidence intervals (CI) were calculated for relevant demographics variables. All statistical analyses were conducted using SAS version 9.2 (Cary, N.C.).

Descriptive analysis was used to review the free-text comments.

\section{Results}

From a potential 1069 pharmacists, 296 surveys were returned, with a response rate of $27.7 \%$. The survey was divided into three components; questions that could be completed by (i) all respondents (296 respondents), (ii) only handheld computer users (151 respondents), and (iii) only non-users (145 respondents). The total number of responses to each question varies because some questions were left unanswered. 
Table 1. Characteristics of Nova Scotia pharmacist survey respondents: overall, users, and non-users.

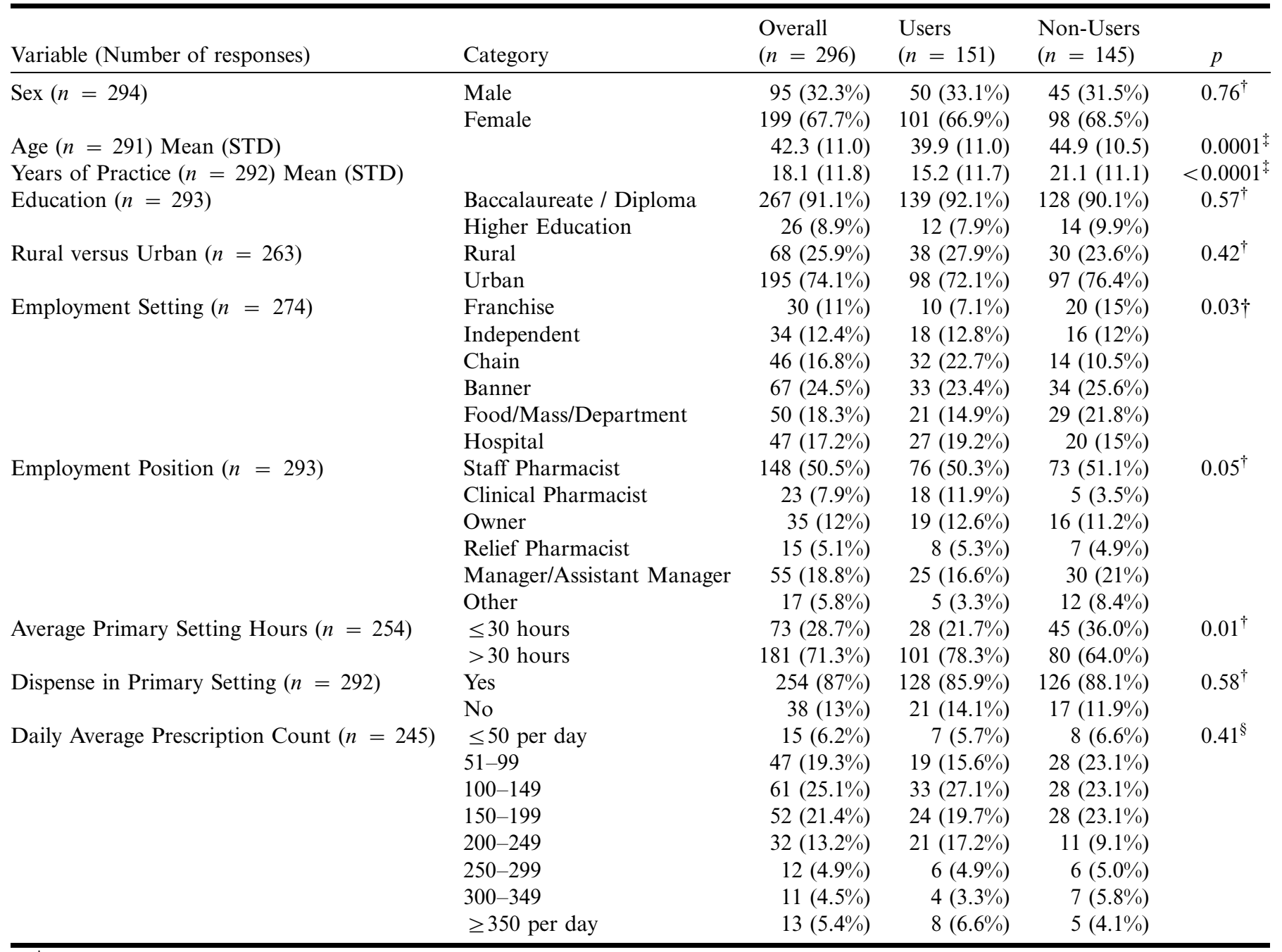

${ }^{\dagger}$ chi-square test

t $t$-test

${ }^{\S}$ Cochrane-Armitage test

\section{All respondents}

\section{Characteristics}

Table 1 provides information on characteristics of respondents and compares handheld computer users to non-users. The general characteristics of our survey population are similar to those documented in a Canadian Institutes of Health Information (CIHI) report on the demographics of pharmacists in Canada [27]. Of our respondents, $67.7 \%$ (199/294) were female versus $69.3 \%$ in the CIHI report. Respondents had a mean age of 42.3 years compared to the CIHI data, which records an average age of Nova Scotia pharmacists of 42.4 years. CIHI reports a relatively high percentage of pharmacists working in rural settings in Nova Scotia compared to other provinces $(28.6 \%)$. In our survey $25.9 \%$ (68/263) of respondents worked in rural employment settings.

Just over half of the respondents $(51.0 \%, 151 / 296)$ reported use of handheld computers in their practice. There was no significant difference between the percentage of users and non-users represented by sex $(33.1 \%$ of users were male versus $31.5 \%$ of non-users, $p=0.76$ ), but the pharmacists reporting handheld computer use tended to be younger $(p=0.0001)$ and newer to the practice of pharmacy $(p<0.0001)$ (Table 1$)$. This was evident in the adjusted analysis where each increasing years of practice was associated with a lower odds of use of handheld computers $(\mathrm{OR}=0.97,95 \% \mathrm{CI}=0.94-0.99$, $p=0.01$ ) (Table 2).

Handheld computer users tended to work more hours (78.3\% versus $64.0 \%$ of users and non-users working $>30$ hours per week respectively, $p=0.01$ ); however, this association was not seen in multivariate analysis $(p=0.13)$. Sex, location, education, and daily prescription count were also not significantly associated with the use of handheld computers in multivariate analysis.

\section{Learning preferences}

Respondents were asked to rank different methods for learning new technology, such as handheld computers, from not preferred to highly preferred (Table 3). 
Table 2. Predicting the use of handheld computers by Nova Scotia pharmacist respondents' characteristics: Adjusted Odds Ratios (OR) and 95\% Confidence Intervals (95\% CI).

\begin{tabular}{lll}
\hline Characteristic & Odds Ratio $(95 \% \mathrm{CI})$ & $p$-value \\
\hline $\begin{array}{l}\text { Sex } \\
\text { Male (ref) }\end{array}$ & - & - \\
$\begin{array}{l}\text { Female } \\
\text { Years of Practice (per year) }\end{array}$ & $0.83(0.44,1.54)$ & 0.55 \\
$\begin{array}{l}\text { Education } \\
\text { Baccalaureate / Diploma (ref) }\end{array}$ & - & 0.01 \\
$\begin{array}{l}\text { Higher Education } \\
\text { Urban versus Rural }\end{array}$ & $0.29(0.03,2.61)$ & - \\
$\begin{array}{l}\text { Average Primary Setting Hours } \\
<30 \text { hours per week (ref) }\end{array}$ & - & $0.56(0.29,1.07)$ \\
$\quad>30$ hours per week & $1.70(0.85,3.40)$ & 0.08 \\
$\begin{array}{l}\text { Average Prescription Count } \\
<200 \text { daily (ref) }\end{array}$ & - & - \\
$>200$ daily & $1.77(0.93,3.36)$ & 0.13 \\
\hline
\end{tabular}

Group learning led by an expert facilitator was selected as preferred or highly preferred by $71.8 \%$ of respondents (204/284). One-on-one instruction was chosen as preferred or highly preferred by $66.1 \%$ of respondents $(189 / 286)$. Other methods proposed by the survey were selected less frequently by both users and non-users. Independent learning and Internet chat groups seemed to be more preferable among users than non-users $(p=0.005$ and $p=0.040$, respectively).

\section{Handheld computer users}

\section{Adoption}

A majority of handheld computer users found starting to use these devices was easy or very easy $(59.6 \%$, 90/151). Over three-quarters of users reported that they were comfortable or very comfortable with the use of their handheld computer $(81.1 \%, 120 / 148)$.

\section{Hardware / software used}

Palm ${ }^{\circledR}$ (Palm, Inc., Sunnyvale, Calif.) handheld computers were the most common brand used $(84.1 \%, 122 / 145)$. Other brands reported were Dell ${ }^{\circledR}$ (Dell, Inc., Round Rock, Tex.), Hewlett-Packard ${ }^{\circledR}$ (Hewlett-Packard Co, Palo Alto, Calif.), and Sony ${ }^{\circledR}$ (Sony Corp., Minato-ku, Tokyo), although no other single brand represented more than $5 \%$ of respondents. Given that the handheld computer brand informed the operating system, $72.3 \%$ of users (107/148) reported that their devices used Palm OS $^{\circledR}$ software (Palm, Inc., Sunnyvale, Calif.). Thirty-four respondents did not know what their operating systems were $(23 \%, 34 / 148)$, which may explain why the number reporting using $\mathrm{Palm}^{\circledR}$ devices exceeds the number reporting Palm OS software.

Of users, 111 reported access to a device with iPharmacist ${ }^{\circledR}$ software $(76 \%, 111 / 146)$. This software, supplied by the generic drug company Apotex, Inc. (Toronto, Ont.), delivers Lexi-Drugs ${ }^{\circledR}$ software among other resources. Other software programs used on the handheld computers for drug information tasks included Lexi ${ }^{\circledR}$ products (Lexi-Comp, Inc., Hudon, Ohio) Epocrates ${ }^{\circledR}$ (San Mateo, Calif.) Micromedex ${ }^{\circledR}$ (Thomson Reuters, NY) Pharmacists Letter ${ }^{\circledR}$ (Stockton, Calif.) and eTherapeutics ${ }^{\circledR}$ (Canadian Pharmacists Association, Ottawa, Ont.).

\section{Handheld computer tasks}

Pharmacists reported using handheld computers to assist with clinical tasks in their practice. At least weekly, $79.3 \%$ respondents reported checking drug interaction data (119/150), 58.0\% reported obtaining patient education information (87/150), and $27.0 \%$ reported performing clinical calculations (40/148).

\section{Barriers and facilitators to adoption}

One-fifth of users purchased their own handheld computer $(21.6 \%, 32 / 148)$, employers supplied the devices for another group of respondents $(48.0 \%, 71 / 148)$, and drug companies supplied another $23.0 \%$ as promotional gifts (34/148). Employers supplied technical support for 39.0\% of users (57/146). Software was supplied to $60.5 \%$ of those with existing hardware (89/147). One-third of users received funding to purchase software $(31.7 \%, 33 / 104)$. Of users, $6.2 \%$ reported expense of hardware and software as a concern $(9 / 144)$.

\section{Handheld computer non-users}

\section{Barriers and facilitators to adoption}

Commonly stated barriers to using or increasing the use of handheld computers by non-users included a lack of specific training, a perception that information was not current or was difficult to keep current, information easily available on non-handheld computer resources, and technological impediments (too slow, screen too small, not enough memory, unable to print, awkward to use, problems integrating with desktop system). Non-users indicated that expense was a barrier to handheld computer adoption $(6.1 \%, 8 / 132)$.

Notably, $68.6 \%$ of non-user respondents perceived a professional need for handheld computers with pharmacy software in the future $(96 / 140)$.

\section{Discussion}

Of pharmacist respondents, $51 \%$ reported using handheld computers in their professional practice. Users tended to be younger and relatively new to the profession. The average age of users was 39.9 years. Non-users were an average of 44.9 years. These findings are consistent with those found by a survey on handheld computer use by hospital and community pharmacists conducted in Texas in 2004 , which reported that $67 \%$ of survey participants who owned handheld computers were under the age of 40 [14]. A systematic review of handheld computer use by pharmacists and other healthcare workers published in 2006 found mixed results with regards to sex and 
Table 3. Nova Scotia pharmacist respondents' preferences for handheld computer and software training

\begin{tabular}{|c|c|c|c|}
\hline & $\begin{array}{l}\text { Users } \\
(n=151)\end{array}$ & $\begin{array}{l}\text { Non-Users } \\
(n=145)\end{array}$ & $p$ \\
\hline \multicolumn{4}{|c|}{ One-on-one in person instruction } \\
\hline $\begin{array}{r}\text { Not Preferred-1 } \\
2 \\
3 \\
4 \\
\text { Highly Preferred }-5\end{array}$ & $\begin{array}{r}23(15.5 \%) \\
11(7.4 \%) \\
24(16.2 \%) \\
30(20.3 \%) \\
60(40.5 \%)\end{array}$ & $\begin{array}{r}8(5.8 \%) \\
6(4.4 \%) \\
25(18.1 \%) \\
25(18.1 \%) \\
74(53.6 \%)\end{array}$ & $0.004^{\dagger}$ \\
\hline $\begin{array}{r}\text { Group learning led b } \\
\text { Not Preferred-1 } \\
2 \\
3 \\
4 \\
\text { Highly Preferred }-5\end{array}$ & $\begin{array}{r}\text { expert facil } \\
8(5.4 \%) \\
12(8.2 \%) \\
21(14.3 \%) \\
57(38.8 \%) \\
49(33.3 \%)\end{array}$ & $\begin{array}{r}7(5.1 \%) \\
5(3.7 \%) \\
27(19.7 \%) \\
52(38.0 \%) \\
46(33.6 \%)\end{array}$ & $0.71^{\dagger}$ \\
\hline $\begin{array}{r}\text { A written instruction } \\
\text { Not Preferred-1 } \\
2 \\
3 \\
4 \\
\text { Highly Preferred }-5\end{array}$ & $\begin{array}{l}\text { nual } \\
20(13.6 \%) \\
17(11.6 \%) \\
52(35.4 \%) \\
35(23.8 \%) \\
23(15.7 \%)\end{array}$ & $\begin{array}{l}18(13.0 \%) \\
28(20.3 \%) \\
40(29.0 \%) \\
24(17.4 \%) \\
28(20.3 \%)\end{array}$ & $0.75 \dagger$ \\
\hline $\begin{array}{r}\text { Independent learning } \\
\text { Not Preferred-1 } \\
2 \\
3 \\
4 \\
\text { Highly Preferred }-5\end{array}$ & $\begin{array}{l}\text { h trial and e } \\
24(16.3 \%) \\
29(19.7 \%) \\
51(34.7 \%) \\
23(15.7 \%) \\
20(13.6 \%)\end{array}$ & $\begin{array}{r}39(28.1 \%) \\
32(23.0 \%) \\
37(26.6 \%) \\
23(16.6 \%) \\
8(5.8 \%)\end{array}$ & $0.005^{\dagger}$ \\
\hline $\begin{array}{r}\text { An Internet chat gro } \\
\text { Not Preferred-1 } \\
2 \\
3 \\
4 \\
\text { Highly Preferred }-5\end{array}$ & $\begin{array}{r}87(60.0 \%) \\
33(22.8 \%) \\
18(12.4 \%) \\
4(2.8 \%) \\
3(2.1 \%)\end{array}$ & $\begin{array}{r}96(70.1 \%) \\
29(21.2 \%) \\
8(5.8 \%) \\
2(1.5 \%) \\
2(1.5 \%)\end{array}$ & $0.04^{\dagger}$ \\
\hline $\begin{array}{r}\text { An online video on th } \\
\text { Not Preferred-1 } \\
2 \\
3 \\
4 \\
\text { Highly Preferred }-5\end{array}$ & $\begin{array}{l}\text { aternet } \\
27(18.4 \%) \\
36(24.5 \%) \\
31(21.1 \%) \\
40(27.2 \%) \\
13(8.8 \%)\end{array}$ & $\begin{array}{l}35(25.4 \%) \\
29(21.0 \%) \\
32(23.2 \%) \\
27(19.6 \%) \\
15(10.9 \%)\end{array}$ & $0.36^{\dagger}$ \\
\hline $\begin{array}{r}\text { A live online presenta } \\
\text { Not Preferred-1 } \\
2 \\
3 \\
4 \\
\text { Highly Preferred }-5\end{array}$ & $\begin{array}{r}38(26.0 \%) \\
33(22.6 \%) \\
38(26.0 \%) \\
30(20.6 \%) \\
7(4.8 \%)\end{array}$ & $\begin{array}{c}38(27.5 \%) \\
46(33.3 \%) \\
33(23.9 \%) \\
11(8.0 \%) \\
10(7.3 \%)\end{array}$ & $0.13^{\dagger}$ \\
\hline $\begin{array}{r}\text { A video cassette (VH } \\
\text { Not Preferred-1 } \\
2 \\
3 \\
4 \\
\text { Highly Preferred }-5\end{array}$ & $\begin{array}{l}\text { or DVD } \\
48(33.1 \%) \\
46(31.7 \%) \\
29(20.0 \%) \\
19(13.1 \%) \\
3(2.1 \%)\end{array}$ & $\begin{array}{r}42(30.7 \%) \\
35(25.6 \%) \\
26(19.0 \%) \\
25(18.3 \%) \\
9(6.6 \%)\end{array}$ & $0.08^{\dagger}$ \\
\hline
\end{tabular}

$\dagger$ Cochrane-Armitage test handheld computer adoption, although several surveys documented that men tended to be more likely to adopt the technology [5]. We did not find a significant association between sex and handheld computer use in Nova Scotia.

Almost all pharmacists in Nova Scotia who used handheld computers used them to facilitate drug and therapeutic information retrieval. Lindquist et al. noted that handheld devices allow access to "information on the spot" [17]. Similarly, a systematic review of the impact of handheld computers on hospital physician's work practices and patient outcomes found that handheld computers provided benefits when rapid response and accessibility were an issue [28]. Decentralized access to information, when away from an office or dispensary with a desktop computer, may be the handheld computer's major benefit. For this reason, hospital pharmacists may use the device more frequently when on the ward or involved in patient-care meetings. Community pharmacists may use mobile devices when counselling outside the dispensary on non-prescription medications or in private counselling areas, although many private counselling rooms may also have a desktop computer.

Respondents who reported not using handheld computers indicated a number of concerns: expense, lack of training, reduced perception of value, and technological concerns. A project to introduce physicians to handheld computers found that the participants' major barrier to handheld computer adoption was a lack of a perceived need however a lack of ease of use was also cited [29]. The project also noted several issues not addressed specifically in our survey, that of multisystem interconnectivity and integration, who had the authority to access specific patient data, and the value of the information that is available on these devices.

Both behavioural and technical barriers to handheld computer usage may be expected to diminish as the technology improves and the use of these devices becomes more commonplace. Synchronization is no longer required for modern wireless devices. Touch-screen access and font adjustments have improved the usability of even small devices. Larger portable screens found in tablet devices may offer significant advantages [30].

Many professionals now use their own handheld computers. Based on the findings of this survey, non-users may need support from employers to access devices, and to learn how best to exploit handheld computer resources. It will also be important to determine how best to access and adapt applications, provide multisystem accessibility and ensure appropriate data standards, patient and provider privacy and security [31]. This paradigm shift will present challenges with regards to software and data standards, and patient and provider privacy and security $[14,32]$. Health care information professionals will be valued contributors to these discussions.

In our survey, over two-thirds of respondent non-users perceived a professional need for handheld computers with pharmacy software in the future. A key finding of the Informatics Pharmacy Special Network (a discussion forum of the Canadian Society of Hospital Pharmacists) 
survey found that Canadian hospital pharmacies continue to be slow to adopt new technology that enhances patient safety [33]. The pressure to adopt technology with the capability to assist pharmacists with their clinical roles must be considered within the context of expanded scope of practice including medication management and independent prescribing in many Canadian provinces [34, 35]. Enhanced roles demand "ready access to credible, objective, and up-to-date professional resources including internet-based information" [36], which may be offered by handheld computers.

The evidence that the use of handheld computers in health care settings is able to improve decision-making, reduce the numbers of medical errors, and enhance learning for both students and professionals is limited [17]. A review of 12 American and Canadian descriptive studies of pharmacists' use of handheld computers for documentation of interventions noted that there was an overall lack of well-designed studies reporting the effect of using handheld computers on patient outcomes [16].

Additionally, there are concerns that the information specifically designed for handheld computers may be less complete or usable than that found in paper-based or internet-based databases [37, 38, Personal communication: Campbell-Palmer, S., BSc(Pharm), Manager of Professional Practice (NSCP), 6 June 2011]. Both the usability and the quality of the information must always be considered when purchasing or accessing drug and therapeutic information for use in both mobile and desktop computers. For example, in a recent Canadian study, two of the most cited software programs in our survey, Lexi-Comp ${ }^{\circledR}$ and Micromedex ${ }^{\dagger}$, varied in pharmacist ratings on quality and usability with respect to specific drug information questions, with Lexi-Comp ${ }^{\dagger}$ receiving higher mean score in the satisfaction domain, compared to Micromedex $^{\dagger}$ [39]. Free or low-cost applications are available for most brands of smartphones and tablet computers and may provide useful adjuncts to more complete online resources [40], however, they do not replace them. Although this survey was unable to evaluate the quality and usability of software choices of Nova Scotia pharmacists, there continues to be a need for information resources to be evaluated by professional associations and health system librarians to determine the strengths and weaknesses of the content and usability.

This study captures the use of handheld computers by pharmacists in Nova Scotia in 2008 and sets a foundation for future work. It opens a much needed discussion with regard to the use of handheld computers by pharmacists, specifically, and healthcare providers, in general. Since the time of the survey, the changes in the information landscape in all health care professions have been profound. Current handheld computers are easier to use, provide expanded functionality, and have changed the way in which patient data and evidence are retrieved and clinical activities are documented. Tablet computers, especially, make the access to information more user-friendly. The integration of this rapidly evolving technology continues to present opportunities to improve health care and increase efficiency, but challenges still exist. Further work is required to understand the impact of the quality of information available for easy 'granular' use in handheld computers on patient care and outcomes, and to understand the value that these devices can bring to clinical practices.

There are several limitations to this survey. The survey was distributed only once by the provincial pharmacy association in conjunction with a regular newsletter mailing and repeat mailings did not occur. The response rate may limit our ability to generalize results to all Nova Scotia pharmacists: however, the general characteristics of our survey population were similar to those documented by the Canadian Institutes of Health Information [27]. Responses to published surveys on the topic of handheld computer usage by health care professionals varied from a low of $5.7 \%$ to $100 \%[5,24,41]$.

Handheld computers users may have been more likely to respond, leading to a non-responder bias. This survey documented self-reported data; we did not evaluate observed behaviour. The multivariate analysis was performed only on those respondents who dispensed prescriptions, which limits the ability to generalize this portion of the study's analysis.

Determining the impact of handheld computers on the process of clinical care or patient outcomes was beyond the scope of this investigation. We did not evaluate the completeness, timeliness or accuracy of resources used on handheld computers by responders. Patient security and confidentiality policies were not addressed.

\section{Conclusions}

Of Nova Scotia pharmacist respondents 51\% reported using handheld computers in their professional practices. Those newer to practice were associated with a higher odds of handheld computer use. A majority of non-users perceived that the devices, equipped with appropriate pharmacy applications, offer the potential to help enhance patient care activities. This finding suggests that there will be further handheld computer adoption by pharmacists. Further work is needed to understand the value of handhelds computers as information resources, which may improve the effectiveness and efficiency of patient care.

\section{Acknowledgements}

The funding for the printing and distribution of the survey was provided by the Pharmacy Association of Nova Scotia and is gratefully acknowledged, as is the participation of all the pharmacists who completed our survey. We would like to thank Elizabeth Foy, Jennifer Isenor, and Blair Salter for their assistance. Thank you to Dr. Judith Fisher for review of the manuscript. Dr. Ingrid Sketris held a Chair in Health Services Research funded by the Canadian Health Services Research Foundation, the Canadian Institutes of Health Research, co-sponsored by the Nova Scotia Health Research Foundation during the study time period.

Results were presented, in part, at the poster session of The Canadian Pharmacists Association's Annual National Conference, Halifax, Nova Scotia, May 2009. 


\section{References}

1. Health Canada. Drug Product Database. 2011. Available from: http://www.hc-sc.gc.ca/dhp-mps/prodpharma/databasdon/indexeng.php.

2. Felkey BG, Fox BI, Thrower MR. Health care informatics: A skills-based resource. Washington, DC: American Pharmacists Association; 2006.

3. Alper BS, Hand JA, Elliott SG, et al. How much effort is needed to keep up with the literature relevant for primary care? J Med Libr Assoc. 2004;92(4):429-37.

4. Fox BI, Felkey BG. Portable information appliances: An update. Hosp Pharm. 2010;45(5):418-419. doi:10.1310/hpj 4505-418.

5. Garritty C, El Emam K. Who's using PDAs? Estimates of PDA use by health care providers: a systematic review of surveys. J Med Internet Res. 2006;8:e7. doi:10.2196/jmir. 8.2.e7.

6. Murray MD, Loos B, Tu W, Eckert GJ, Zhou XH, Tierney WM. Work patterns of ambulatory care pharmacists with access to electronic guideline-based treatment suggestions. Am J Health-Syst Pharm. 1999;56:225-32.

7. Walpert B. The operating system debate: Pocket PC versus Palm. ACP-ASIM Observer supplement. Available from: http://acponline.org/journals/handhelds/nov02/debate.htm.

8. Bosinski TJ, Campbell L, Schwartz S. Using a personal digital assistant to document pharmacotherapeutic interventions. Am J Health Syst Pharm. 2004;61:931-4.

9. Ford S, Illich S, Smith L, Franklin A. Implementing personal digital assistant documentation of pharmacist interventions in a military treatment facility. $J$ Am Pharm Assoc. 2006;46:589-93. doi:10.1331/1544-3191.46.5.589.Ford.

10. Krogh PR, Rough S, Thomley S. Comparison of two personal-computer-based mobile devices to support pharmacists' clinical documentation. Am J Health-Syst Pharm. 2008; 65:154-7. doi:10.2146/ajhp070177.

11. Patel RJ, Lyman AE, Clark DR, Hartman TJ, Chester EA, Kicklighter CE. Personal digital assistants for documenting primary care clinical pharmacy services in a health maintenance organization. Am J Health-Syst Pharm. 2006;63: $258-61$.

12. Raybardhan S, Balen R, Partovi N, Loewen P, Liu G, Jewesson PJ. Documenting drug-related problems with personal digital assistants in a multisite health system. Am J Health-Syst Pharm. 2005;62:1782-7.

13. Ling JM, Mike LA, Rubin J, et al. Documentation of pharmacist intervention in the emergency department. Am J Health-Syst Pharm. 2005;62:1793-7. doi:10.2146/ajhp040588.

14. Dasgupta A, Sansgiry SS, Sherer JT, Wallace D, Sikri S. Pharmacists' utilization and interest in usage of personal digital assistants in their professional responsibilities. Health Info Libr J. 2010;27:37-45. doi:10.1111/j.1471-1842.2009. 00856.x.

15. Fox BI.The iPharmacist ${ }^{\circledR}$ Handheld: A tool to support Canadian Pharmacy. 2010Feb 26. Available from: http:// www.rxbriefcase.com/rxPassport/Apotex/media/pdf/patient_ resources2/iPharmacist_Handheld_Auburn_U_Study.pdf.
16. Fox BI, Felkey BG, Berger BA, Krueger KP, Rainer RK Jr. Use of personal digital assistants for documentation of pharmacists' interventions: a literature review. Am J HealthSyst Pharm. 2007;64:1516-25. doi:10.2146/ajhp060152.

17. Lindquist AM, Johansson PE, Petersson GI, Saveman BI, Nilsson GC. The use of the personal digital assistant (handheld computers) among personnel and students in health care: a review. J Med Internet Res. 2008;10:e31. doi:10.2196/ jmir.1038.

18. Balen RM, Jewesson PJ. Pharmacist computer skills and needs assessment survey. J Med Internet Res. 2004 Mar 29; 6(1):e11. doi:10.2196/jmir.6.1.e11.

19. Carroll AE, Christakis DA. Pediatricians' use of and attitudes about personal digital assistants. Pediatrics. 2004 Feb;113(2):238-42. doi:10.1542/peds.113.2.238.

20. Honeybourne C, Sutton S, Ward L. Knowledge in the palm of your hands: PDAs in the clinical setting. Health Info Libr J. 2006 Mar;23(1):51-9.

21. Murphy AL, Fleming M, Martin-Misener R, Sketris IS, MacCara M, Gass D. Drug information resources used by nurse practitioners and collaborating physicians at the point of care in Nova Scotia, Canada: A survey and review of the literature. BMC Nurs. 2006Jul6;5(1):5. doi:10.1186/14726955-5-5.

22. Scott I, Wilson C, Gowans M. Are personal digital assistants an acceptable incentive for rural community-based preceptors? Fam Med. 2005 Nov-Dec;37(10):727-33.

23. Stroud SD, Erkel EA, Smith CA. The use of personal digital assistants by nurse practitioner students and faculty. $J \mathrm{Am}$ Acad Nurse Pract. 2005Feb;17(2):67-75. doi:10.1111/j.10412972.2005.00013.x.

24. Sutton J, Stockton L, McCord G, Gilchrist VJ, Fedyna D. Handheld computer use in a family medicine clerkship. Acad Med. 2004;79:51-9. doi:10.1097/00001888-200411000-00024.

25. National Center for Biotechnology Information, U.S. National Library of Medicine. MeSH NLM Controlled Vocabulary Database. Topic "Computers, Handheld”. 2003. Available from: http://www.ncbi.nlm.nih.gov/mesh.

26. McKesson Canada. Trends \& Insights. 2005. Available from: http://www.mckesson.ca/static/en/pdf/Trends_2005.pdf.

27. Canadian Institutes of Health Information. Pharmacists in Canada, 2009. November 2010. Available from: http://secure. cihi.ca/cihiweb/products/Pharmacists_Report_112010_Eng.pdf.

28. Prgomet M, Georgiou A, Westbrook JI. The impact of mobile handheld technology on hospital physicians' work practices and patient care: a systematic review. $\mathrm{J} \mathrm{Am} \mathrm{Med}$ Inform Assoc. 2009;16(6):7920801. doi:10.1197/jamia.M3215.

29. Ranson S, Boothby J, Mazmanian P, Alvanzo A. Use of personal digital assistants (PDAs) in reflection on learning and practice. J Contin Educ Health Prof. 2007;27:227-33. doi:10.1002/chp.142.

30. Cockerham M. Use of a tablet personal computer to enhance patient care on multidisciplinary rounds. Am J Health-Syst Pharm. 2009;66:1911. doi:10.2146/ajhp080593.

31. Gamble KH. Beyond phones. Healthcare Informatics. 2009; $26: 23-5$ 
32. Rothschild JM, Fang E, Liu V, Litvak I, Yoon C, Bates D. Use and perceived benefits of handheld computer-based clinical references. J Am Med Inform Assoc. 2006;13:61926. doi:10.1197/jamia.M2103.

33. Barnett J, Jennings H. Pharmacy information systems in Canada. Stud Health Technol Inform. 2009;143:131-5. doi:10. 3233/978-1-58603-979-0-131.

34. Sketris, I. Extending prescribing privileges in Canada. CPJ. 2009;142:17-9. doi:10.3821/1913-701X-142.1.17.

35. Law M, Ma T, Fisher J, Sketris I. Independent pharmacist prescribing in Canada. CPJ 2012;145(1):17-23.

36. Nova Scotia College of Pharmacists. Professional Library Requirements. 2007. Available from: http://www.nspharmacists. ca/resources/documentsProfessionalLibraryRequirementsMay2007. pdf.

37. Barrons R. Evaluation of personal digital assistant software for drug interactions. Am J Health-Syst Pharm. 2004;61: $380-5$.
38. Galt KA, Rule AM, Houghton B, Young DO, Remington G. Personal digital assistant-based drug information sources: potential to improve medication safety. J Med Libr Assoc. 2005;93:229-36.

39. Montford CM, Lee T, de Lemos J, Loewen PS. Quality and usability of common drug information databases. Can J Hosp Pharm. 2010;63(2):130-7.

40. Enderle L. Smartphones: Smart enough for pharmacists? Pharmacy Times. 2010, Feb 16. Available from: www. pharmacytimes.com.

41. De Groote SL, Doranski M. The use of personal digital assistants in the health sciences: results of a survey. $J$ Med Libr Assoc. 2004;92:341-9. 